\title{
(4)
}

\section{THE EFFECTS OF SINGEING ON THE HISTOLOGICAL APPEARANCE OF SOME VISCERAL ORGANS IN THE RED SOKOTO GOAT (Capra hirrcLs)}

\author{
HENSHAW, E, NLEBEDUM U. C., IBE C.S., NNADOZIE O., AGBAKWURU I. and *IKPEGBU E. \\ Department of Veterinary Anatomy, Michael Okpara University of Agriculture, Umudike, Abia state, \\ Nigeria. \\ *correspondence to E. Ikpegbu email address fikpegbu@yahoo.com, Mobile phone +2348060775754
}

\begin{abstract}
The histology of visceral organs from singed Red Sokoto goats were assessed for reliability for use as histopathological samples from singed abattoir specimen. This becomes important as samples for histopathology and histology of goats in Nigeria have been sourced from singed carcasses, with no available literature reporting on the effect of singeing on the histological appearance of tissues from such sample. Hence, this study will fill this knowledge gap. The unfixed samples post-singeing were grouped into time periods of an hour interval up to 3 hours. They were subsequently fixed after allocated tie framed and processed for histological observation. The slides were graded on a scale of 1 to 3 , where 1 referred to highly distorted, 2 referred to moderately distorted and 3 referred to mildly distorted. The samples from unsigned viscera that were fixed immediately served as control. Most of the visceral organs showed moderate distortions, except the intestines which degenerated to highly distorted architecture after 3 hours. The stomach compartments displayed normal organ structure similar to the control samples. Blood extravasations were observed in most of the organs. This project shows that samples from singed carcasses that are fixed within 2 hours post-singeing are stable for histology or histopathological studies. It also implied that abattoir samples for histopathogy should be sent to the nearest laboratory about 2 hours radius for fixation and processing to generate reliable data.
\end{abstract}

Key words: Singeing, organ architecture, fixation, histology, histopathology, Nigeria

\section{INTRODUCTION}

In Nigeria and several other African countries, singeing in an open fire is the major process by which hair on the skin of slaughtered goat is removed (Okubanjo,1997; Obiri-Danso, 2008; Omojola et al, 2012). This is because singeing maintains the carcass hide for consumption and evokes flavor in the meat which is acceptable to the consumers (FAO, 1985).

Singeing possesses antimicrobial and anti parasitic potentials. Palumbo et al. (1999) reported that although singeing is undertaken to help facilitate removal of hair, an advantage of effective singeing is that it helps to reduce bacterial numbers on the carcass surface. Effective singeing can result in almost complete removal of skin-surface contamination (Berendset al., 1997). This is possible because heat generated during singeing can destroy both surface parasites and microbes that survive the slaughter animal. Omojola and Adesehinwa (2006) reported that singeing is one of the paramount post-slaughter processing methods of animal carcasses known to affect physical, chemical and organoleptic properties of meat used from small-stocks such as sheep and goats and recently cattle carcass. Even the use of some

Submitted $20^{\text {th }}$ November 2018. Published online $14^{\text {th }}$ January 2019. To cite: Henshaw E, Nlebedum UC, Ibe CS, Nnadozie O, Agbakwuru I, Ikpegbu E. Effects of singeing on the histological appearance of some visceral organs in the red sokoto goat (Capra hirrcus). Anatomy Journal of Africa. 8 (1): 1395 - 1410. 
materials like motor tyres and plastics as fuel source for the singeing process have been reported to contaminate the meat with heavy metal (Kalu et al., 2014). These may inadvertently affect the histological appearance of sample collected hence the need for this study.

Whereas, most samples for histopathology and histology of goats in Nigeria have been sourced from singed carcasses (Omojola and Adesehinwa, 2006). There is no information from available literature on the effect of singeing on the histological appearance of tissues from such sample. Hence, this study will fill this knowledge gap.
The research questions intended to be answered by the end of this project include, does singeing of goat carcass have any effect on the histological appearance? If yes, to what extent? Does duration between collection of sample and fixation affect histological appearance of samples from singed carcass? If yes, to what extent?

The work is aimed at studying the effect of singeing on histological appearance of some goat visceral organs and comparing the effect of time of post sample collection fixation on the histological appearance of tissue from singed goat carcasses. This result will ascertain the extent of reliability of such samples for histology and histopathology.

\section{MATERIALS AND METHODS}

Tissue samples were collected from Red Sokoto goats (Capra hirrcus) at the abattoir in Ahiaeke goat market, Umuahia, southeastern Nigeria. The samples were from unsigned freshly slaughtered to serve as control and referred to as group 1; while the other samples were from singed freshly slaughtered goats (Fig. 1). The goats were clinically certified to be apparently healthy before slaughter. The samples were quickly transported in clean sample bottles to the laboratory in 5 minutes. The samples collected were lungs, mesenteric lymph nodes, spleen, liver, kidney, Abomasum, omasum, reticulum, rumen, jejenum, duodenum, colon and ceacum.

Small pieces of the samples were immediately fixed in neutral buffered formalin in the laboratory referred to as group 2, while the bulk of the original specimen was kept unfixed. After one hour, small sections of these unfixed samples were cut and fixed with same fixative (group 3); after two hours small pieces from the unfixed samples were fixed in same fixative (group 4); and three hours small pieces again were taken from the unfixed bulk and fixed in same fixative (group 5). After 48 hours, the tissues were passed through graded ethanol, cleared in xylene, impregnated at $60^{\circ} \mathrm{C}$ and embedded in the paraffin wax. Sections $5 \mathrm{~mm}$ thick were obtained with Leitz microtome model 1512. They were stained with haematoxylin and eosin for light microscopy (Bancroft and Stevens, 1990). The slides were examined with Olympus microscope (insert model number and country of production). The qualities of the stained sections from the singed samples were graded according to Nlebedum et al., (2013) using these criteria: general organ microscopic architecture, cell morphology, and state of the epithelium. They were graded on a scale of 1 to 3 , where 1 referred to highly distorted, 2 referred to moderately distorted-and 3 referred to mildly distorted. Photomicrographs of selected sections were taken with Novel digital microscope model DN-10.

\section{RESULTS}

\section{Kidney}

Tissue section from Group 2 presented a moderately distorted general organ microscopic architecture (Fig. 2; Table 1) as seen in the high extravasation of blood within and around the profiles of the tubules and glomeruli. At higher 
magnification, the nuclear morphology and epithelial covering the convoluted tubules-were not distorted, hence a grading of 2 . The tissue sections from Group 3 presented moderately distorted general organ microscopic architecture such as high extravasation of blood within and around the profiles of the tubules and glomeruli. At higher magnification, the nuclear morphology and epithelial covering the convoluted tubules were not distorted; hence a grading of 2.The tissue sections from Group 4 presented a moderately distorted general organ microscopic architecture (Fig.3) as seen in the highextravasations of blood within and around the tubules and glomeruli. At higher magnification, the nuclear morphology and epithelial covering the convoluted tubules were not distorted, similar to the control sections, hence a grading of 2 (Table 1 ). The tissue sections from group 5 presented a moderately distorted general organ microscopic architecture, as seen in the highextravasations of blood within and around the profiles of the tubules and glomeruli. At higher magnification, the nuclear morphology and epithelial covering the convoluted tubules were not distorted, hence a grading of 2 .

\section{Spleen}

Tissue sections from Group 2 presented a moderately distorted general organ microscopic architecture (Fig. 4) as seen in the highextravasations of blood in the organ parenchyma. However, cellular morphology of the cells of the white and red pulp, as well as the intact capsule and vascular endothelium were not distorted, hence the grading of 2 (Table 1 ). Sections from Group 3 presented a moderately distorted general organ microscopic architecture as seen in the extravasations of blood in the organ parenchyma and the entire organ. However, cellular morphology of the cells of the white and red pulp, as well as the intact capsule and vascular endothelium were not distorted, hence the grading of 2 . Group 4 presented a moderately distorted general organ microscopic architecture. However, cellular morphology of the cells of the white and red pulp (Fig. 5), as well as the intact capsule and vascular endothelium were not distorted; hence the grading of 2.Tissue sections from Group 5 presented a moderately distorted general organ microscopic architecture as seen in the extravasations of blood in the organ parenchyma and the entire organ. However, cellular morphology of the cells of the white and red pulp, as well as the intact capsule and vascular endothelium were not distorted, hence the grading of 2 .

\section{Liver}

General organ microscopic architecture of tissue sections of the liver from Group 2 were mildly undistorted (Fig. 6), including the cellular morphology of the hepatocytes and kupffer cells. The central vein and portal triad were normal. The covering capsule and vasculature, especially the sinusoids, were normal hence a grading of 3 (Table 1). The sections from Group 3 appeared normal hence a grading of 3 . The Group 4 sections were also normal (Fig. 7), hence a grading of 3 . The normal general organ and cellular architecture was seen in the group 5, hence a grading of 3 .

\section{Lymphnode}

Tissue sections from Group 2 presented a mildly distorted general organ microscopic architecture (Fig. 8) as seen by the mild extravasations of blood within the entire organ. At higher magnification, cellular morphology of the cells of the lymph nodules as well as the covering of capsule and vascular endothelium appeared mildly distorted, hence a grading of 3 . Tissue sections from Group 3 presented a mildly distorted general organ microscopic architecture seen by the slight extravasations of blood within the entire organ. At higher magnification, cellular morphology of the cells of the lymph nodules as well as the covering of capsule and vascular endothelium appeared normal, hence a grading of 3.Tissue sections from Group 4 presented a mildly distorted general organ microscopic architecture (Fig. 9) as seen by the slight extravasations of blood within the entire organ. At higher magnification, cellular morphology of the cells of the lymph nodules as well as the covering of capsule and vascular endothelium 
appeared normal, hence a grading of 3.-Group 5 presented a mildly distorted general organ microscopic architecture as seen by the slight extravasations of blood within the entire organ. At higher magnification, cellular morphology of the cells of the lymph nodules as well as the covering of capsule and vascular endothelium appeared normal, hence a grading of 3 .

\section{Lungs}

Tissue sections from Group 2 presented a mildly distorted general organ microscopic architecture (Fig. 10) as seen by the slight extravasations of blood. However, at higher magnification, the cellular morphology appeared normal as did the epithelial lining of the bronchioles, hence a grading of 3.The microscopic architecture of Group 3 at low magnification presented moderately distorted general organ morphology as seen by the increase in extravasations of blood within the organ. However, at higher magnification, the cellular morphology appeared almost normal as did the epithelial lining of the bronchioles, hence a grading of 2 . The microscopic architecture of Group 4 sections presented moderately distorted general organ morphology at low magnificationas seen by the increase in extravasations of blood within the organ (Fig.11). However, at higher magnification, the cellular morphology appeared normal as did the epithelial lining of the bronchioles, hence a grading of 2 . The Group 5 sections presented moderately distorted general organ morphology as seen by the increase in extravasations of blood within the organ. However, at higher magnification, the cellular morphology appeared normal as did the epithelial lining of the bronchioles, hence a grading of 2 .

\section{Stomach}

Tissue section from Group 2 presented undistorted general morphology of the rumen as seen in the presence of the conical papillae projecting from the luminal surface of the organ and the lamina propria-submucosa (Fig. 12). At higher magnification, the cellular morphology and epithelium of the conical papillae appeared good, hence a grading of 3 . Tissue section from Group 3 presented undistorted general morphology of the rumen hence a grading of 3 . Tissue sections from Group 4 presented undistorted general morphology of the rumen as seen in the presence of the conical papillae projecting from the luminal surface of the organ and the lamina propria-submucosa (Fig. 13). At higher magnification, the cellular morphology and epithelium of the conical papillae appeared normal similar to the control group, hence a grading of 3.Tissue section from Group 5 presented a good general gastrointestinal tract morphology, hence a grading of 3 .

While similar histological observations were observed in the other fore-stomach including reticulum and omasum hence a grading of 3 , the abomasum showed slight organ distortion hence a grading of 3 (Table 1 ).

\section{Intestines}

Tissue sections from Groups 2 (Fig. 14), 3 and 4 (Fig. 15) each, presented moderate distorted general morphology of the jejunum as seen in the slight erosions of their villi and the extravasations of blood in their mucosa. At higher magnification of each of the mentioned groups, the cellular morphology at the base of the intestinal crypts appeared normal, hence, Groups 2, 3 and 4 were graded 2.-Tissue sections from Group 5 presented highly distorted general morphology of the small intestine as seen in the autolysis of its villi and the extravasations of blood in the mucosa, hence a grading of 1 . These observations were also seen in the duodenum, colon and caecum (Table 1). 


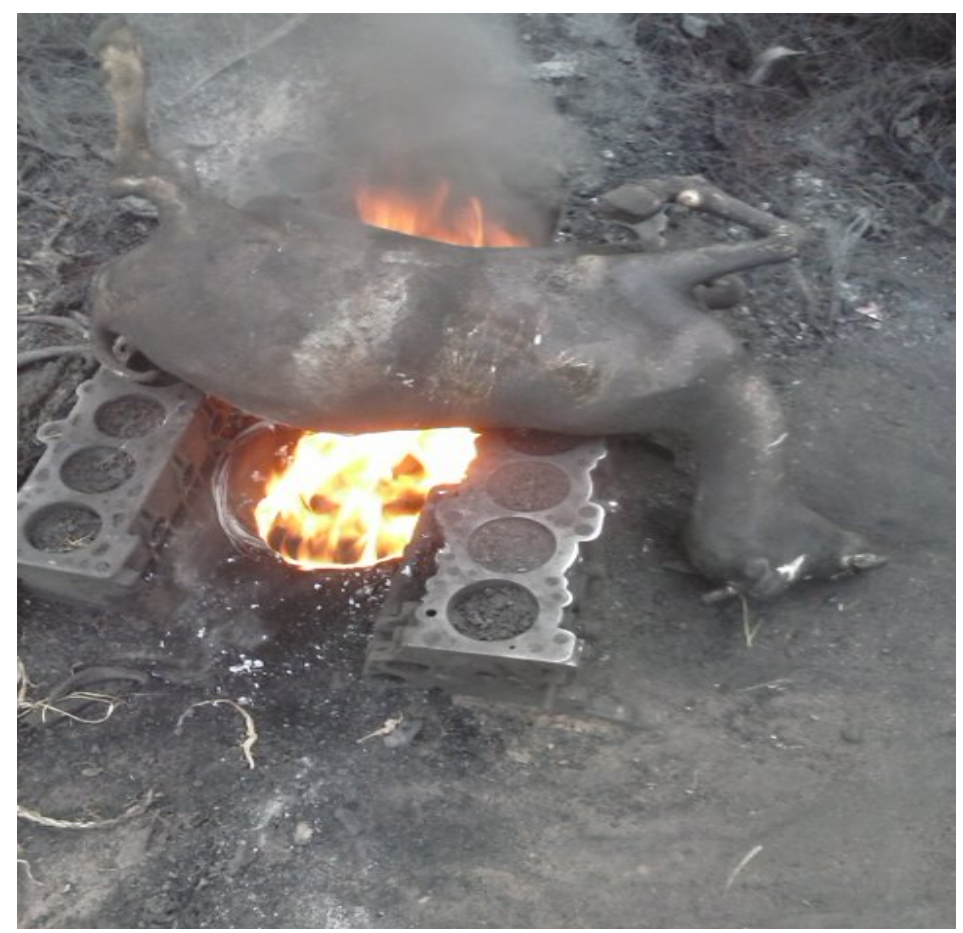

Fig.1: Singeing of goat in progress

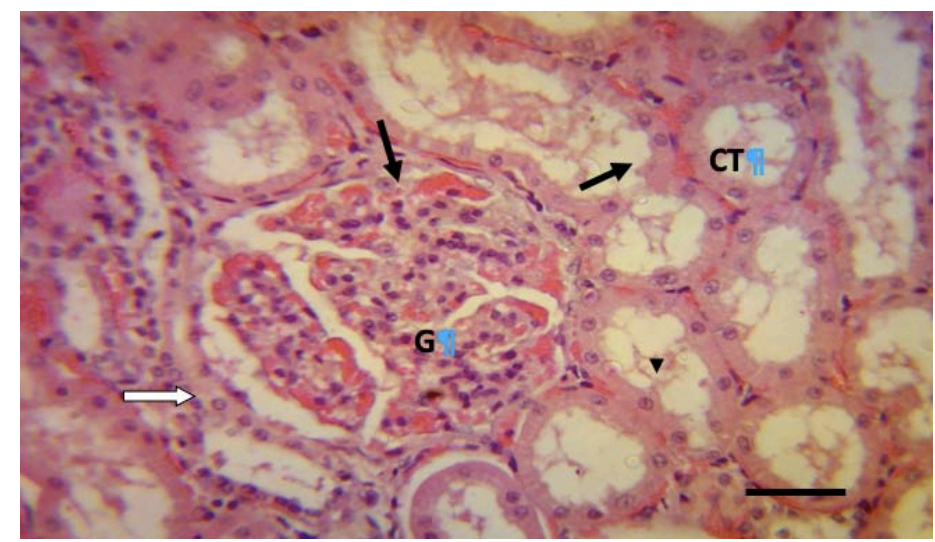

Fig. 2: Transverse section of kidney from the singed goat fixed immediately (Group 2) showing fairly good cellular morphology but slight organ architecture distortion due to presence of blood extravasation (black arrow). Note simple squamous cells of Bowman's capsule(white arrow)within the glomerulus(G), the simple cuboidal cells(black arrow head) of the convoluted tubules $(C T) \cdot H \& E$ (Scale bar $=40 \mu \mathrm{m})$.

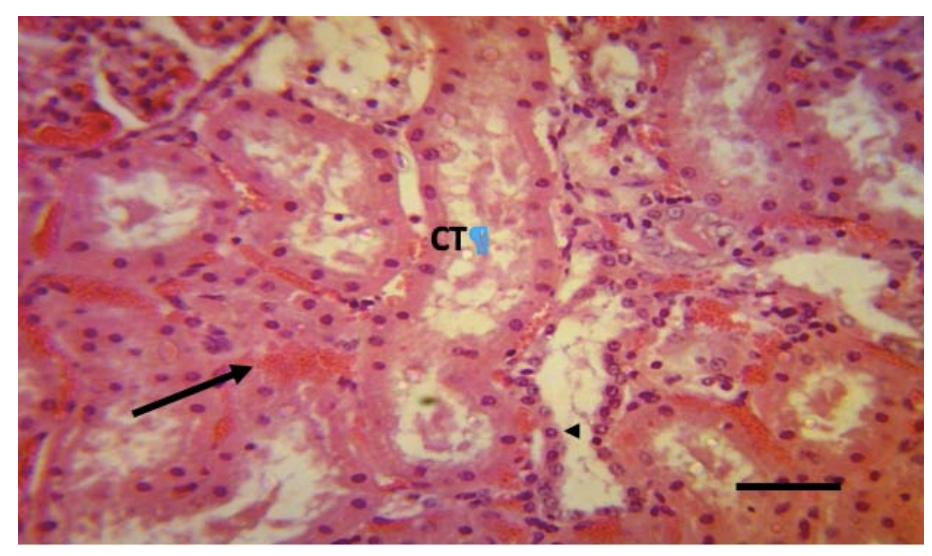

Fig.3: Transverse section of kidney fixed 2 hours post-singeing (Group 4) showing simple cuboidal cell of the convoluted tubules (CT), and high extravasation of blood(black arrow). $\mathrm{H} \&$ $\mathrm{E}($ Scale bar $=40 \mu \mathrm{m})$. 


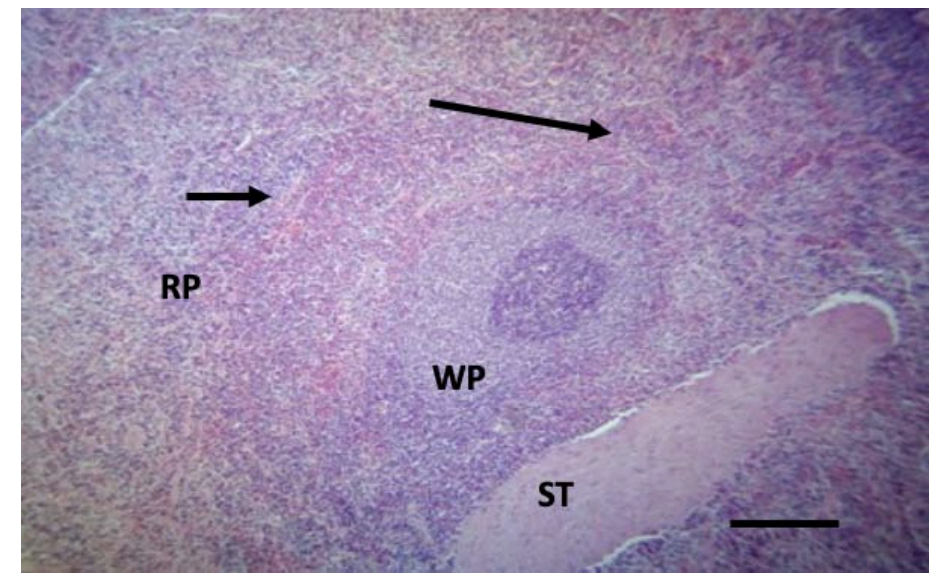

Fig.4:Transverse section of Spleen from singed goat fixed immediately (Group 2) showing organ microscopic architecture distortion including extravasation of blood(black arrow) seen within the entire organ.Note the Red pulp(RP),White pulp(WP) and Splenic trabeculae(ST). H \& E (Scale bar $=20 \mu \mathrm{m})$.

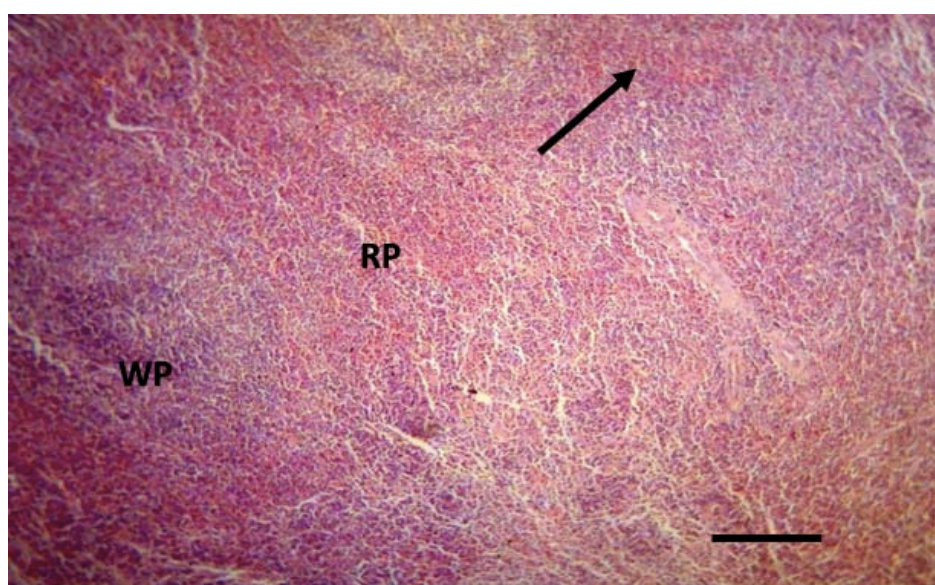

Fig.5:Transverse section of Spleen from a singed goat fixed after 2 hours (Group 4) showing organ microscopic architecture distortion resulting from the high extravasation of blood(black arrow) seen within the entire organ. Note the Red pulp(RP) and White pulp(WP).H \& E (Scale bar $=20 \mu \mathrm{m})$.

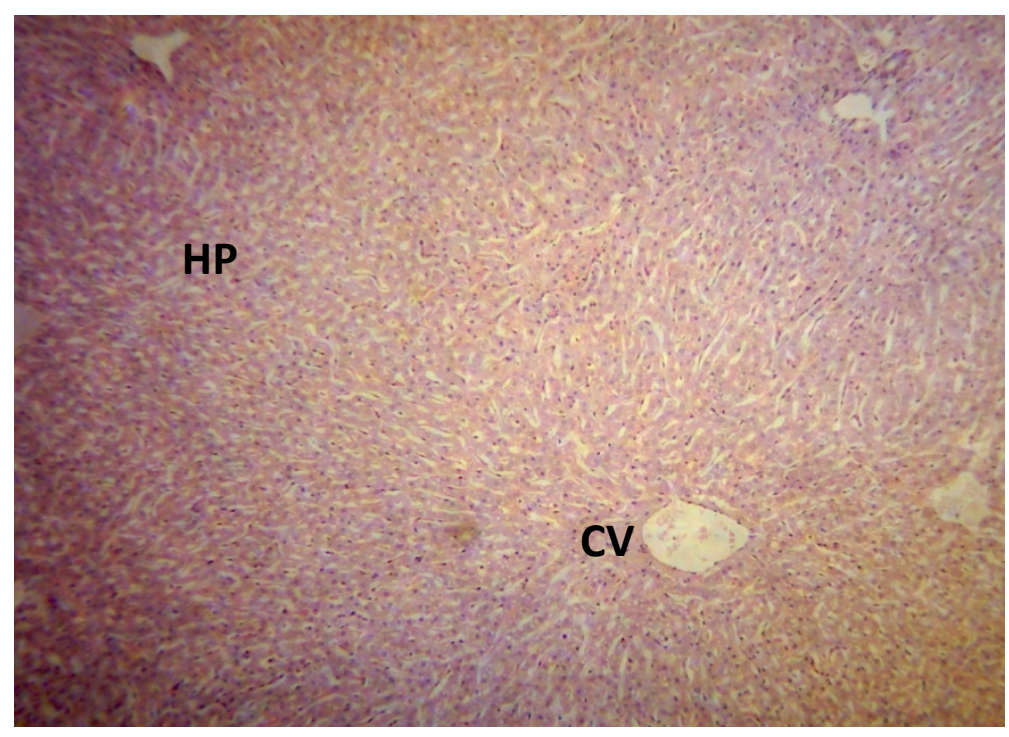

Fig. 6:Transverse section of liver from singed goat fixed immediately (Group 2) showing normal general organ microscopic

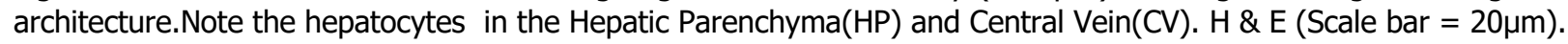




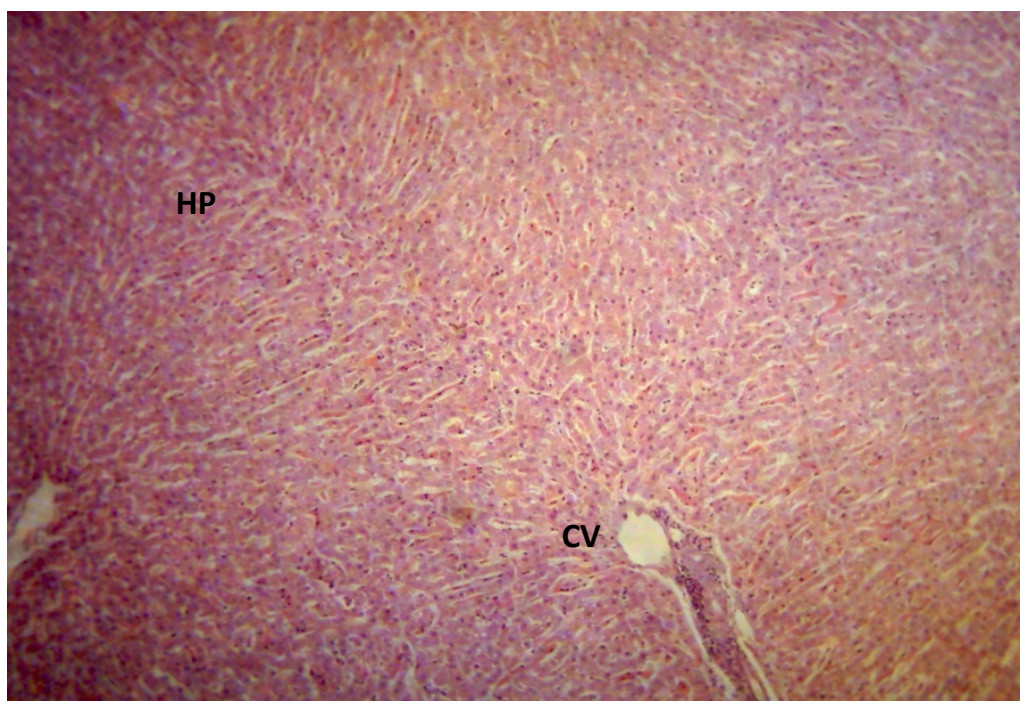

Fig.7: Transverse section of liver from singed goat fixed after 2 hours (Group 4) showing normal general organ microscopic architecture. Note the Hepatocytes in the Hepatic Parenchyma (HP), sinusoid (black arrow), and Central Vein(CV).H \& E (Scale bar $=20 \mu \mathrm{m})$.

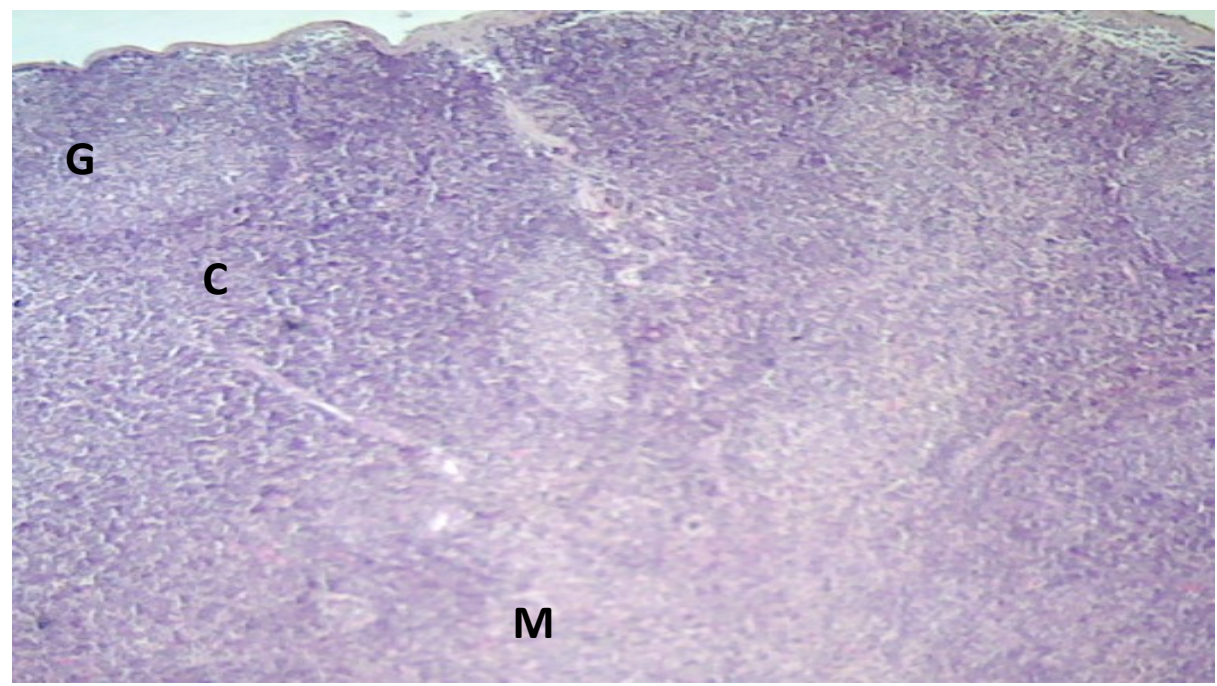

Fig.8: Transverse section of Lymph node from a singed goat fixed immediately (Group 2) showing normal organ microscopic architecture distortion. Note the lymphoid nodule germinal centren $(\mathrm{G})$, cortex $(\mathrm{C})$, capsule(black arrow) and medula (M). H \& E (Scale bar $=10 \mu \mathrm{m})$. 


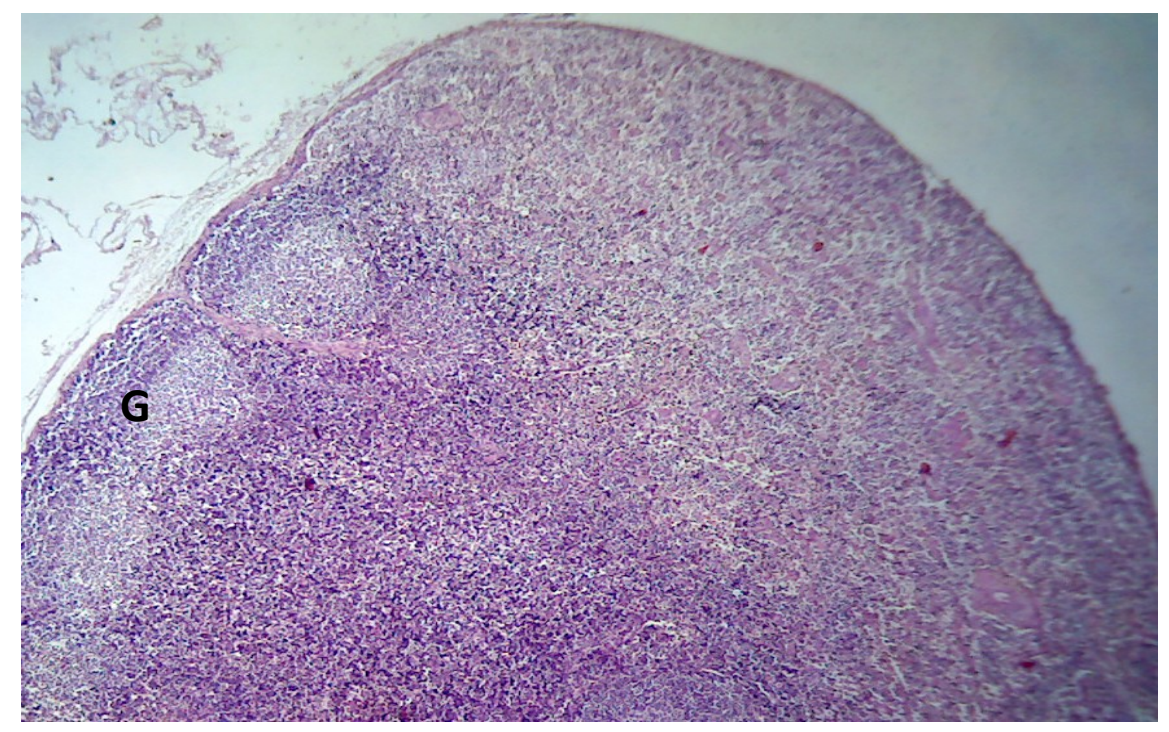

Fig. 9: Transverse section of Lymph node from a singed goat fixed after 2hours (Group 4) showing moderately distorted organ microscopic architecture. Note the germial centre $(G)$ and capsule (black arrow). H \& E (Scale bar $=10 \mu \mathrm{m})$.

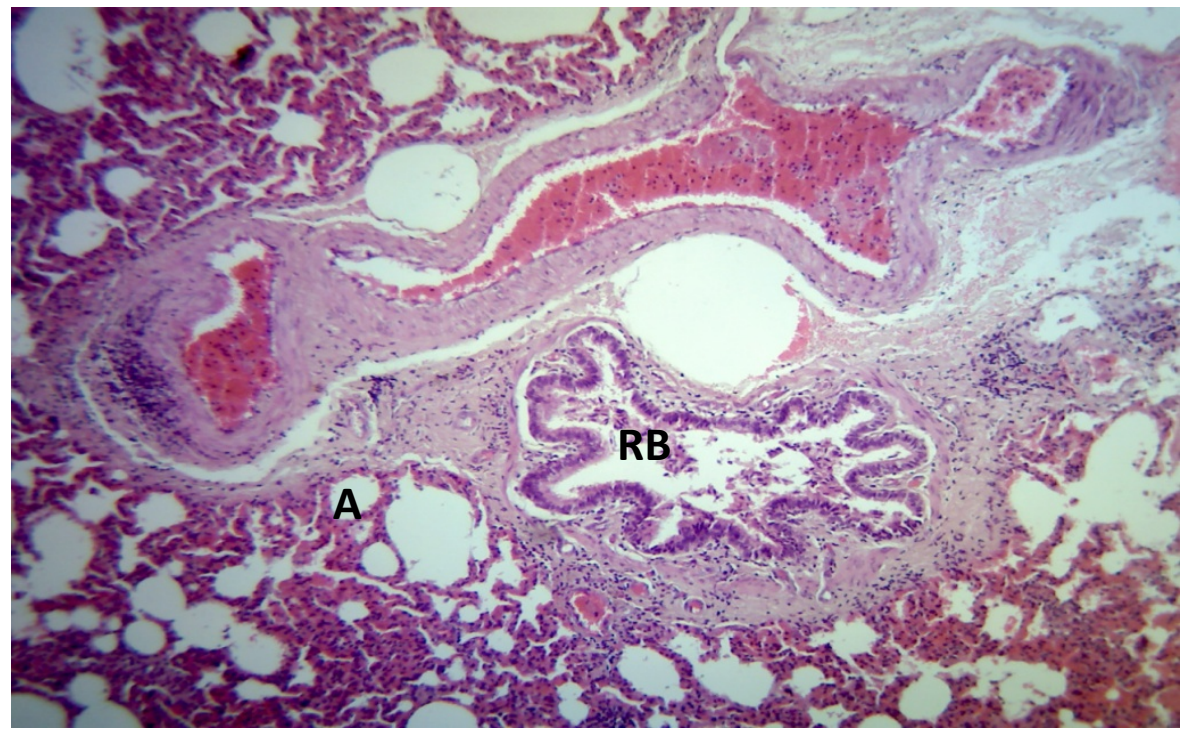

Fig.10: Transverse section of lung tissue from singed goat fixed immediately (Group 2) showing moderately distorted organ microscopic architecture resulting from slight extravasation of blood(black arrow).Note therespiratory bronchiole(RB) and alveolar $\operatorname{sac}(\mathrm{A}) . \mathrm{H} \& \mathrm{E}($ Scale bar $=20 \mu \mathrm{m})$. 


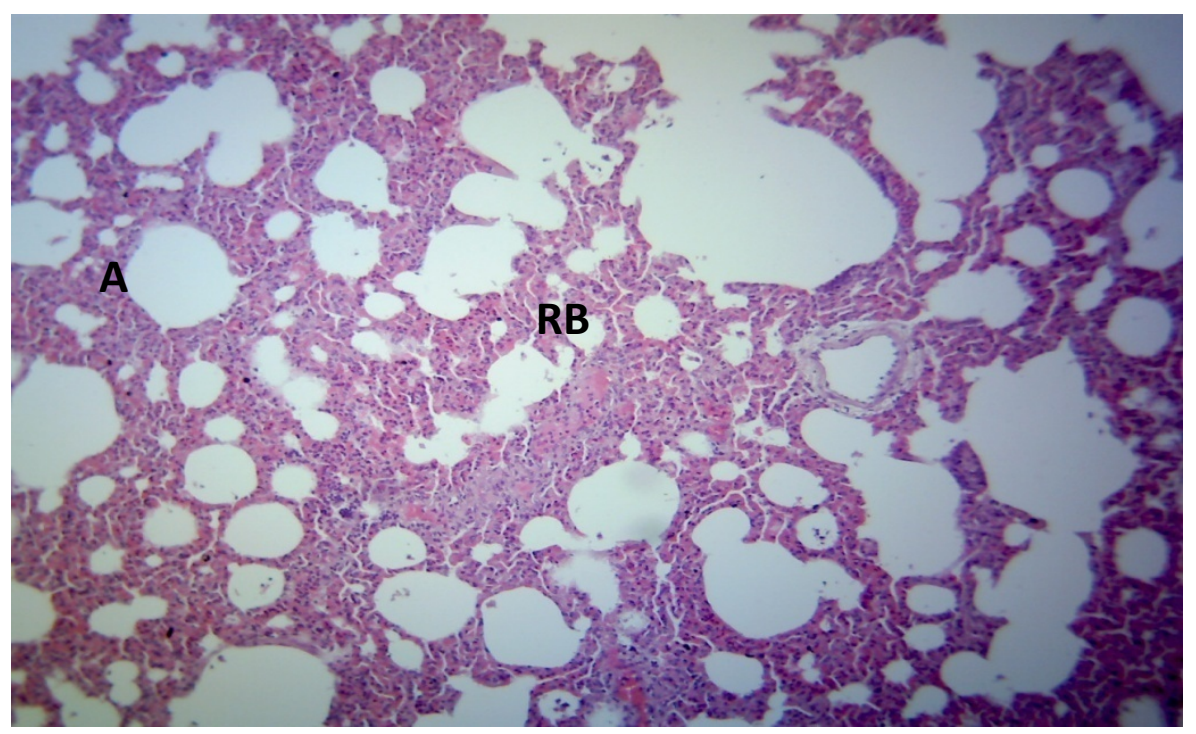

Fig.11: Transverse section of lung tissue from singed goat fixed after 2 hrs (Group 4) showing moderately distorted organ microscopic architecture resulting from slight extravasation of blood(black arrow). Note the showing respiratory bronchiole (RB) and alveolar sac (A).H \& E (Scale bar = 20 $\mu \mathrm{m})$.

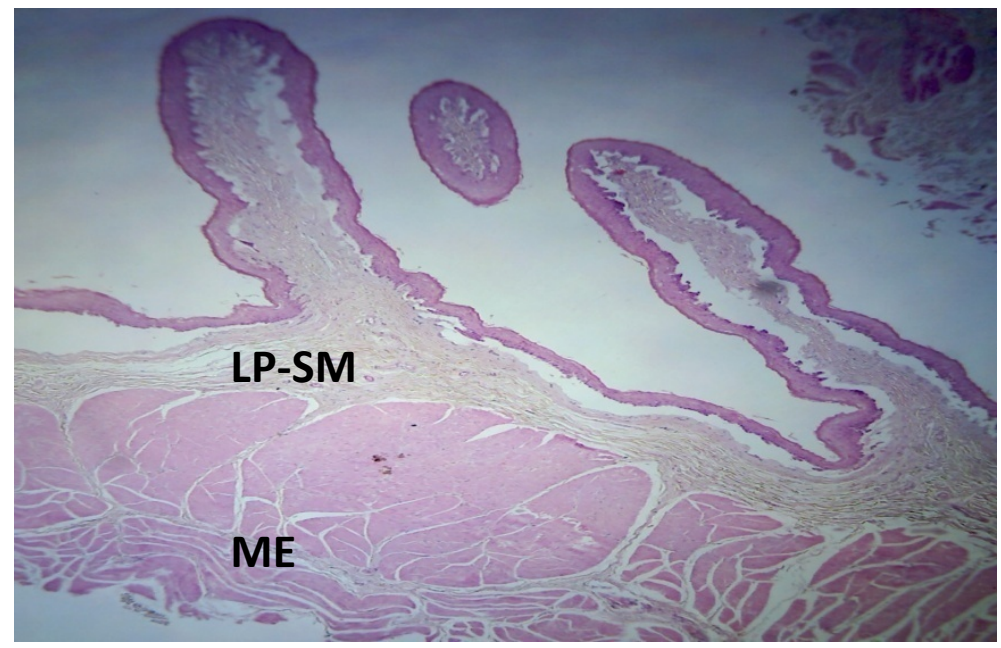

Fig.12: Section of rumen from a singed goat fixed immediately (Group 2) presented undistorted general morphology of rumen. The lamima propia-submucosa(LP-SM) and muscularis externa (ME).H \& E (Scale bar $=10 \mu \mathrm{m})$. 


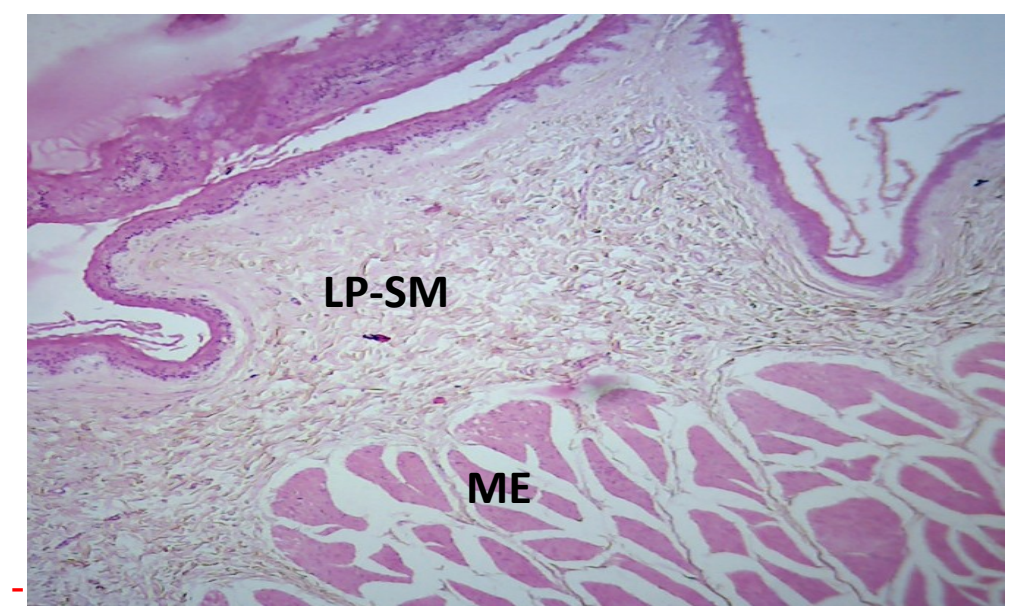

Fig.13: Section of rumen from a fixed 2 hours post-singeing (Group 4) presented undistorted general morphology of the rumen.The Conica papillae (double headed arrow),lamima propia-submucosa (LP-SM) and muscularis externa (ME ). H \& E $($ Scale bar $=10 \mu \mathrm{m})$.

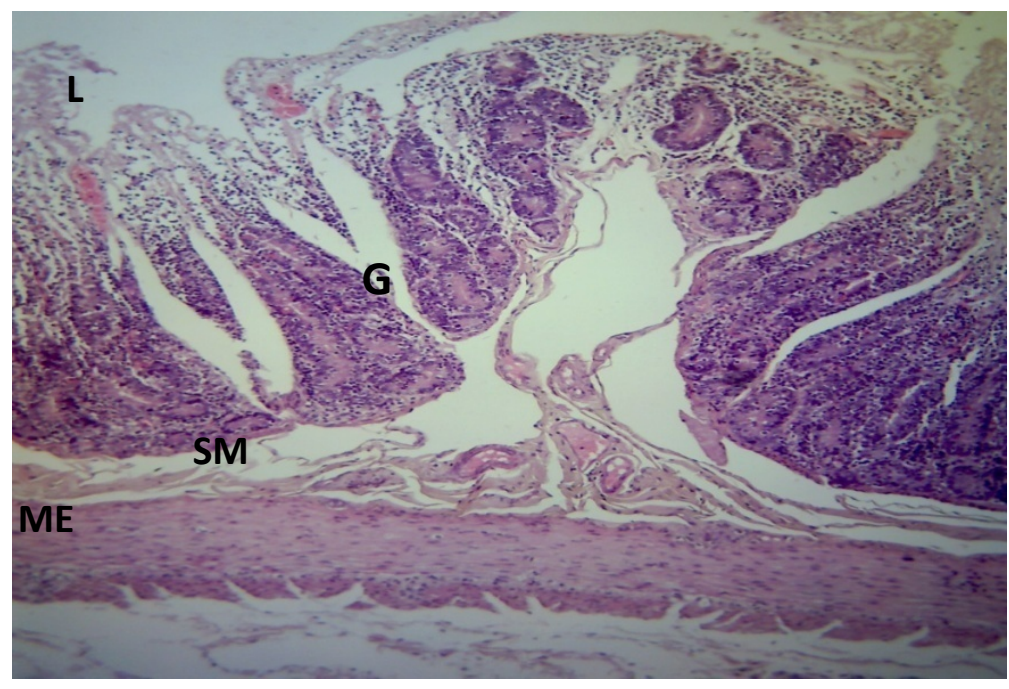

Fig.14: Section of Jejenum from a singed goat fixed immediately (Group 2) showing distorted organ microscopic architecture resulting from the lost of villi in the intestinal lumen (L).Note the Submucosa (SM),muscularis externa (ME), and intestinal glands $(\mathrm{G}) . \mathrm{H} \& \mathrm{E}($ Scale bar $=20 \mu \mathrm{m})$. 


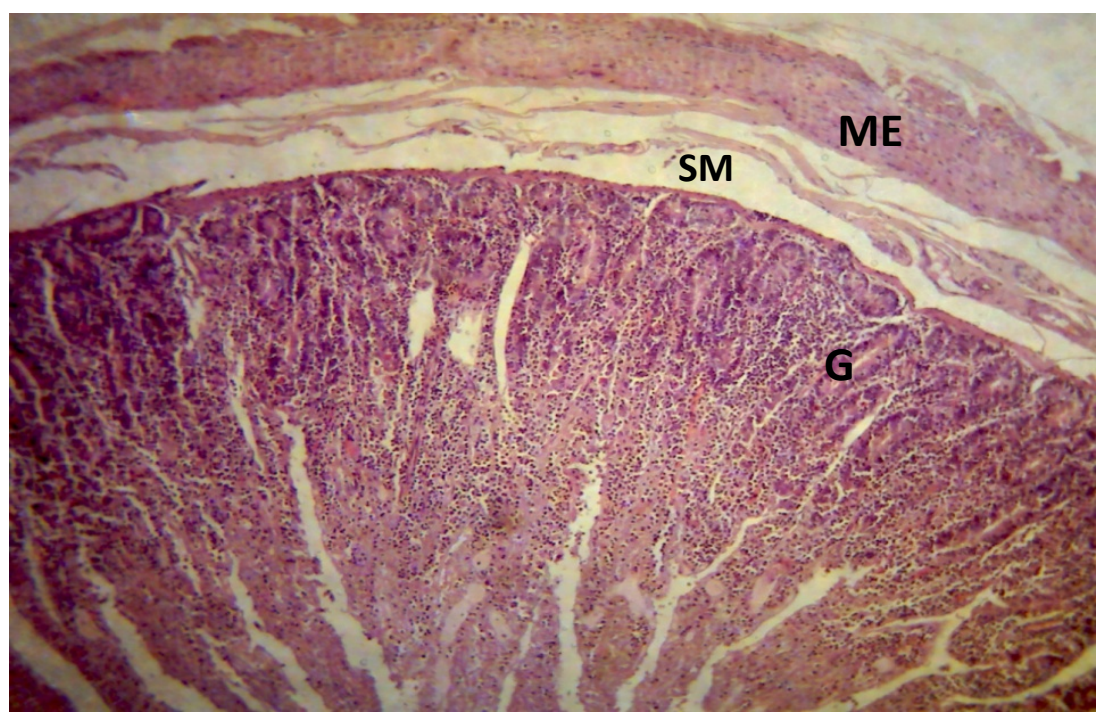

Fig.15: Section of Jejenum from the singed goat after fixed 2hours (Group 4) showing distorted organ microscopic architecture resulting from the lost of villi.Note the Submucosa (SM), muscularis externa (ME), and intestinal glands (IG). H \& E (Scale bar = $20 \mu \mathrm{m})$.

\begin{tabular}{|c|c|c|c|c|c|}
\hline \multirow{2}{*}{ ORGAN } & \multirow{2}{*}{$\begin{array}{l}\text { Fixation of Unsinged } \\
\text { Freshly Slaughtered } \\
\text { Control (Group 1) }\end{array}$} & \multicolumn{4}{|c|}{ TIME Of FIXATION POST SINGING } \\
\hline & & $\begin{array}{l}0 \text { hour } \\
\text { (Group 2) }\end{array}$ & $\begin{array}{l}\text { 1hour } \\
\text { (Group 3) }\end{array}$ & $\begin{array}{l}\text { 2hours } \\
\text { (Group 4) }\end{array}$ & $\begin{array}{l}\text { 3hours } \\
\text { (Group 5) }\end{array}$ \\
\hline kidney & 4 & 2 & 2 & 2 & 2 \\
\hline spleen & 4 & 2 & 2 & 2 & 2 \\
\hline liver & 4 & 3 & 3 & 3 & 3 \\
\hline $\begin{array}{l}\text { Lymph } \\
\text { node }\end{array}$ & 4 & 3 & 3 & 3 & 2 \\
\hline Lungs & 4 & 3 & 2 & 2 & 2 \\
\hline jejunum & 4 & 2 & 2 & 2 & 1 \\
\hline duodenum & 4 & 2 & 2 & 2 & 1 \\
\hline colon & 4 & 2 & 2 & 2 & 1 \\
\hline ceacum & 4 & 2 & 2 & 2 & 1 \\
\hline Abomasum & 4 & 4 & 3 & 3 & 3 \\
\hline Omasum & 4 & 4 & 4 & 4 & 4 \\
\hline Reticulum & 4 & 4 & 4 & 4 & 4 \\
\hline Rumen & 4 & 4 & 4 & 4 & 4 \\
\hline
\end{tabular}

Table 1. Showing graded organ assessment-for the different groups 


\section{DISCUSSION}

The general architecture of the organs from singed goat under study showed a reflection of their physiologic content and function. Most parenchymatous visceral organs like the liver and kidney containing relatively good content of connective tissue fibres had good histologic appearance whilst intestinal sections like colon duodenum with possible high content of digestive enzymes showed rapid degeneration especially their luminal epithelium. This was contrasted by the fore-stomach compartments whose histology remained very similar to unsingedsamples.

The spleen filters blood,destroys effete blood,stores blood and reacts immunologically to blood borne antigen (Junqeiro and Carneiro, 2003; Michael and Wojciech, 2006).The red appearance of the red pulp seen in the fresh and histologic sections from the singed goat may reflect large numbers of red blood cells (Michael and Wojciech,2006). The physiologic function of the spleen predisposes it to extravasations of blood.The large blood volume of the goat, contraction of the abundant smooth muscle of the capsule and trabeculae and, other multi factorial underlying factors may be responsible for the high hemorrhage observed in the spleen (Kranen et al, 2000; Gregory et al, 2011).

The lymph node is an important site for phagocytosis and initiation of immune responses. They serve as filters through which lymph percolates on its way to the blood vascular system (Michael and Wojciech 2006). The slight extravasations of blood seen may probably be due to the physiologic role of the lymph nodes. Autolysis starts as soon as an animal dies (Brodersen, 2011).The progressive loss of some portion of the lymph node evident at the 4th hour was probably due to cell and extracellular micro-organism action exacerbated by the elapsed time in fixing the tissue which is similar to its physiologic reaction and observations of Bancroft and Gamble (2002).

The kidney parenchyma exists to provide service to blood by removal of waste product in it (Singh,
2006). The kidneys are highly vascular organs and they receive approximately $25 \%$ of the cardiac output (Michael and Wojciech 2006). The high extravasation of blood seen within and around the profiles of the tubules and glomeruli may have resulted from the rupture of any of the vessels and also may have resulted from increase in venous blood pressure or agonal changes that occur in tissues immediately before death or following cessation of vital organs resulting in vascular congestion veins (Kranen et al., 2000).

The lung has both pulmonary and bronchial circulations (Michael and Wojciech 2006). It has rich network of blood capillaries (Singh, 2006). The lung has the best developed capillary network in the body with capillaries between all alveoli including those of the respiratory bronchioles. The slight extravasation of blood seen in the tissue fixed immediately and the subsequent increase in extravasation with time for tissues fixed afterwards may be due to sudden drop in blood pressure after death that ultimately affected the partial pressure between oxygen and carbon IV oxide within the alveoli needed to control blood flow or cessation of vital function as observed by (Young and John.2000;Gregory,2004).

The liver is unique among other organs because it receives its major blood supply (about 75\%) from the hepatic portal vein. The remaining $25 \%$ of its blood supply is from hepatic artery. The efficiency of the liver acinus in coordinating blood perfusion, metabolic activity and liver pathology probably explains why there were no obvious hemorrhage seen on the liver tissue of the singed goat.

The ruminant stomach consists of four compartments: the rumen, the reticulum, the omasum and the abomasum. The first three comprise the fore stomach and have nonglandular mucous membrane lined with stratified squamous epithelium while abomasum has a glandular mucous membrane (Sisson and Grossman, 1975). The abomasum showed a 
progressive autolysis of the mucosa which may be due to the presence of the gastric glands in the abomasum whereas the reticulum, omasum and rumen showed good gastro intestinal morphology which may be due to the type of epithelium lining their mucosa

Tissue section from duodenum, jejunum, colon and caecum of the singed goat did not show much post mortem changes clearly shown by the good cellular morphology of the villi epithelium. This is different from the observation of Kruniningen (1998) in which he recorded that villous epithelial cells separated from the membrane within 5 to 10 minutes after death and the progressive spread of autolysis from the tip of the villi within minutes after death to the mucosa with time.The increase in body temperature and the delay in fixing the tissue due to singeing may not have affected the tissue histological integrity a lot.
In conclusion irrespective of the method of slaughtering, hemorrhage may be induced prior to or during slaughter as well as a result of multi factorial underlying causes Allotted time for exsanguination cannot rid the carcass of its blood completely. Early fixation helps in arresting autolysis and in making sample good for histopathologic study.

Singeing of carcass allows for coagulation of blood within the blood vessel and extravasations of blood seen in highly vascularised organs while post sample collection time and fixation time delay creates conducive environment for autolysis to occur in tissue sample not fixed. The seemly moderately good general morphology of most of the samples fixed at 3 hours allows for collection of samples from neighboring states to the laboratory for histopathologic study so long as it is within 3 hours allowing for post sample collection especially in situations of avoidable delays.

\section{REFERENCES}

1. Adam I. Okyere, D. and Teye, M: Assessment of Heavy Metal Residues in Hides of Goats singed with Tyres, and the Effect of boiling on the Heavy metal concentrations in the Hides.J.Vet.adv.,2013,3(5):165-169.

2. Apata, E.S. (2014). Effects of Post-Morterm processes and freezing on water holding capacity, warner bratzler value and chemical composition of cheveon. American Journal of research communication. Vol. 2 (4): 100-113.

3. Anil, Haluk and Lambooij, Bert 2009.Stunning and slaughter methods.In : Welfare of production animals: Assessment and management of risks, Volume 5, Food safety Assurance and veterinary Public Health, Eds: Smulders, FJM and Algers, Bo. WageningenPubls.

4. Anil, M.H. and Austin, A., 2003. Bovine Spongiform Encephalopathy: A Review of some factors that influence meat safety. Agrippa. http://www.fao.org//DOCREP/ ARTICLE/AGRIPPA/590 en.htm\#P11 1213 (accessed December 19, 2008).

5. Anil, M.H. and Harbour, D., 2001. Current Stunning and Slaughter Methods in Cattle and Sheep: Potential for Carcass Contamination with Central Nervous Tissue and Microorganisms. Fleischwirtschaft International 3, 26-27.

6. Anil, M.H. and McKinstry, J.L., 1991.Reflexes and loss of sensibility following Head-to- back electrical stunning in sheep. Veterinary Record 128, 106-107.

7. Anil, M.H. and McKinstry, J.L., 1992.The effectiveness of high frequency electrical stunning of pigs. Meat Science 31, 481-491.

8. Anil, M.H. and McKinstry, J.L., 1998.Variations in electrical stunning tong placements and relative consequences in slaughter pigs. The Veterinary Journal 155, 85-90.

9. Anil, M.H., 1991.Studies on the return of physical reflexes in pigs following electrical stunning. Meat Science 30, 13-21. 
10. Anil, M.H., Butler, S.R., Johnson, C.B. and McKinstry, J.L., 2000.Suppression of somatosensory evoked potentials by Transcranial magnetic stimulation in the rabbit.Proc. Physiological Society, $526 \mathrm{p}$.

11. Anil, M.H., Love, S., Helps, C.R. and Harbour, D., 2002. Potential for Carcass Contamination with Brain Tissue following Stunning and Slaughter in Cattle and Sheep. Food Control 13, 431-436.

12. Anil, M.H., Love, S., Williams, S., Shand, A., McKinstry, I.L., Helps, C.R., Waterman- Pearson, A., Seghatchian, J. and Harbour, D., 1999. Potential contamination of beef carcasses with brain tissue at slaughter. Veterinary Record 145, 460-462.

13. Anil, M.H., McKinstry, J.L. and Wotton, S.B., 1997.Electrical stunning and slaughter of pigs.Guidelines for good welfare assurance.Fleischwirtschaft 77 (7), 632-635.

14. Anil, M.H., McKinstry, J.L., Wotton, S.B. and Gregory, N.G. 1995a.Welfare of calves 1.Investigation into some Aspects of Calf Slaughter. Meat Science, $\underline{41}$ (2),101-112.

15. Anil, M.H., Yesildere, T., Aksu, H., Matur, E., McKinstry, J.L., Erdogan, O., Hughes, S. and Mason, C., 2006. Comparison of Halal slaughter with captive bolt stunning and neck cutting in cattle: exsanguination and quality parameters. Animal Welfare 15, 325-330.

16. Anil, M.H., Yesildere, T., Aksu, H., Matur, E., McKinstry, J.L., Erdogan, O., Hughes, S. and Mason, C., 2004.Comparison of religious slaughter of sheep with methods that include preslaughter stunning and the lack of differences in exsanguination, packed cell volume and quality parameters. Animal Welfare 13 (4), 387-392.

17. Anil, M.H., Yesildere, T., Çötelioglu, Ü and Nazli, B. 1993. The effects of handling on stress parameters before religious slaughter in sheep and cattle. Animal Production, $\underline{56}(3), 436$.

18. Awosanya B, Okubanjo A. O. (1993). Effect of skinning, scalding or singeing on the physical characteristics of rabbit carcasses. Nig. Food Jour. 11: $147-152$.

19. Bancroft, J. D., \& Gamble, M. (2002). Theory \& practice of histological technique (5th ed.).

a. N.Y: Churdchill Livingstone.

20. Banks, W.J.: Applied Veterinary Histology. 3rd edit.Waverly Press Inc. Mt. Royal and

a. Guilford Aves.BaltimoreUSA(1993).

21. Barbara Young and J.W. Wheath (2000). Wheater's functional histology, a text and colour

a. atlas (4th ed.). Harcourt publishers Limited Pp 46-309.

22. Berends, B.R., Van Knapen, F., Snijders, J.M.A. and Mossel D.A.A. (1997).Identification and quantification of risk factors regarding Salmonella spp. on pork carcasses. International Journal of Food Microbiology, 36: 199-206.

23. Costa M (2000). Trace elements: aluminum, arsenic, cadmium, and nickel. In Morton Lippmann (ed.) Environmental Toxicants: Human Exposures and Their Health Effects, 2nd Edition. John Wiley and Sons, Inc. pp. 811-850.

24. Davenport, H. W. (1997). Physiology of gastrointestinal tract (2nd ed.). N.Y: Raven Press.

25. Don. WF (1994); Bloom and Fawcett: A textbook of histology.12 eds. Chapman and Hall,one pennplaza,NewYork.pp 57-758.

26. EFSA(European Food Safety Authority), 2011.Scientific Opinion on Scientific Studies undertaken by UK Food Standards agency to support a proposed production method for smoked "Skin on" Sheep meat.EFSA journal, 9(6):2191.

27. EFSA 2004. Opinion of the Scientific Panel on Animal Health and Welfare on a request from the Commission related to welfare aspects of the main systems of stunning and killing the main commercial species of animals1 http://www.efsa.europa.eu/de/scdocs/doc/45.pdf

28. Essumang DK, Dodoo DK, Adokoh KC, Koka V, Nkrumah BN, Nuer ACD (2007). Heavy metal levels in singed cattle hide (wele) and its human health implications. Proceedings - The First International Conference on Environmental Research, Technology and Policy, ERTEP 2007, Accra, Ghana.Book of Abstracts, p.19. 
29. Eroschenko, VP (2008). Atlas of histology with functional Correlation (11th ed.). London:

a. Lippincott Williams \& Wilkins.

30. EFSA (European Food Safety Authority), 2008. Scientific Opinion of the Panel on

a. Contaminants in

31. FAO (2004):Guidelines for slaughtering, meat cutting and further processing.

32. FAO (2006): Food and Nutrition Paper 82

33. Fisher A, Wilkin C-A and Purnell G., 2007: The production and microbiological status of

a. skin on sheep carcasses. Meat Science.

34. FAO (1985) Animal by-products: Processing and utilization. FAO Animal production and health series. No.9.

35. Getty.R, (1975). In: Sisson and Grossman's:The Anatomy of the Domestic Animals,5th ed.,Vol 1.W.B.saunders Co.Philadelphia,London,Toronto.1975.pp 884.

36. Gill, CO and Bryant J, 1993. The presence of Escherichia coli, Salmonella and

a. Campylobacter in pig

37. Hydrocarbons in Food. The EFSA Journal, 7(24): 1-114.

38. Hillebrand, S.J.W., Lambooy, E. and Veerkamp, C.H., 1996. The effects of alternative electrical and mechanical stunning methods on hemorrhaging and meat quality of broiler breast and thigh muscles. Poultry Science 75, 664-671.

39. Honikel, J.L. (1998) Reference Methods for the Assessment of Physical Characteristics of Meat. Meat Sci. 49: $441-457$.

40. Indebir Singh (2003): a textbook of Human histology. $5^{\text {th }}$ edi.Jaypee Brothers Medical

a. publishers $(\mathrm{P})$. Ltd. pp1-278.

41. Jayasekara S, Samarajeewa U, Jayakody AN (1992). Trace metals in foods of animal origin in Srilanka. ASEAN Food J. 7: 105-107

42. Junqueira, L.C. and Carneiro, J. (2003): Basic Histology text and atlas 10th .ed. MGraw -

a. Hill.Pp: $69-400$.

43. Kalu, E.,Nwata, J. A.,Anaga A. O. (2014):Determination of the presenceandconcentration heavy metals in cattle hides singed in Nsukka abattoir.J.Vet.Med.Anim Health, 7(1): 9-17.

44. Kranen, R.W., Lambooij, E., Veerkamp, C.H., van Kuppevelt, T.H. and Veerkamp, J.H., 2000b. Haemorrhages in muscles of broiler chickens. World's Poultry Sci. J. 56, 94-126.

45. Koohmaraie M, Arthur TM, Bosilevac JM, Guerini M, Shackelford SD and Wheeler TL,

a. 2005. Post- harvest interventions to reduce/eliminate pathogens in beef. Meat Science, 71, 1, 79-91.

46. Koutsoumanis $\mathrm{K}$ and Sofos J, 2004.Microbial contamination. In: Encyclopaedia of meat

a. sciences, vol.2. D Jensen W.K., C., Dikeman, M. Elsevier, Oxford, 727-728.

47. Levinger, I.M., 1976. Physiological and general medical aspects of Shechita. In: Munk, M.L. and Munk, E. (Eds.). Jerusalem Gur Aryeh Publications 147- 149.

48. Monin, G; Talmant, A; Aillery, P. and Collas, P. (1995) Effects of Carcass Weight and Meat Quality of Pigs Dehared by Scalding or Singeing Post-Mortem. Meat Sci. 39: $247-254$.

49. Michael H.Ross,WojciechPawlina (2006). Histology: A text and Atlas. $5^{\text {th }}$ ed.,Lippincott

a. Williams and wilkins .351 West Camden street Baltimore.Pp 1-684.

50. Nlebedum,U.,Ikpegbu, E.,Nnadozie O.,Agbakwuru, I.(2013):Effect of Embalming Fluid on Histological appearance of Organs from Embalmed West African Dwarf Goat cadavers. Histologic, 46(1): 1-4. 
51. Obiri-Danso K, Hogarh JN, Antwi-Agyei P (2008).Assessment of contamination of singed hides from cattle and goats by heavy metals in Ghana.African Journal of Environmental Science and Technology 2 (8), 217-221

52. Offer G, Night $P$ (1998).The structural basis of water holding and Drip losses development in meat Part 2: In: R A. Lawrie (ed) Development in meat science, London, Elsevier. Appl. Sci. 4: 173243

53. Okiel W, Ogunlesi M, Alabi F, Osiughwu B, Sojinrin A (2009). Determination of toxic metal concentrations in flame treated meat products. African Journal of Biochemistry Research 3(10) 332-339.

54. Okubanjo, A.O (1997) Meat Characteristics of Singed and Conventionally Dressed Chevon Carcasses.Journal of Food Science Technology. 34(6): 494 - 497.

55.Omojola,A.B.,Apata E.S. and Fagbuaro S.S. (2012). comparison of skinning versus scalding and singeing:Effect on Temperature,PH and Meat Quality in Goats.Journal of Animal Science Advances2(9):740-748.

56.Omojola, A.B. and Adesehinwa A.O.K (2006) Meat characteristics of Scalded, Singed and Conventionally Dressed Rabbit Carcasses. World Journal of Zoology 1(1): $24-29$.

57. Palumbo, S.A., Pickard, A. and Call, J.E. (1999).Fate of gram-positive bacteria in reconditioned, pork-processing plant water.Journal of Food Protection, 62: 194-197

58. Qiu CAI, Long M, Liu J, Zhu M, Zhou Q-zhen, Deng Y-de, Li Y, Tain YJ (2008). Correlation between heavy metals concentration in cattle tissues and rearing environment.Chinese Journal of Ecology,27(2): 202-207.

59. Ranjit Kumar,,mohd Ali.,Arun Kumar. A.,Nath, Troeger, K. (1993). Scalding and dehairingtechnology : Influence on the bacterial count of pig carcasses. Fleischwirtschaft, 73: 1157-1160.

60. Stevens, A., and Lowe, J. (2005). Human histology (3rd ed.). Hong Kong: Elsevier Mosby.

a. the Food Chain on a request from the European Commission on Polycyclic Aromatic.

61. Sikorski Z.E, (2004). Smoking. In: Encyclopaedia of meat sciences, vol.3. D Jensen W.K., C., a. Dikeman.

62. Troeger, K. (1994). Evaluating hygiene risks during slaughtering. Fleischwirtschaft, 74: 624-626.

63. United States Fire Administration (USFA), (1999). Report on tyre-fires submitted to Committee on Commerce, Science and Transportation, United States Senate and Committee on Science, United States. House of Representative, pp 12-14.

64. Warriss, P. D. and Wilkins, L. J. 1987: Exsanguination of meat animals. Seminar on pre-slaughter stunning of food animals, European Conference Group on the Protection of Farm Animals, 02.06.87, Brussels.

65. Watanabe A, Daly C.C, Devine C.E (1996). The effects of the ultimate pH of meat on tenderness changes during aging. Meat Sci. 42: 67-78.

66. Welfare of calves. 2. Increase in vertebral artery blood flow following exsanguination by neck sticking and evaluation of chest sticking as an alternative slaughter method. Meat Science 41, 113-123.

67. Wheeler T.L, Koohmaraie M. (1994). Pre-rigor and Post-rigor changes in tenderness of ovine longissimus muscle. J. Anim. Sci. 72(5): 1232-1238. 